\title{
Carbothermal nitridation process of mechanically milled silica sand using Taguchi's method
}

\begin{abstract}
This paper reported on the work performed to study the formation of silicon nitride and silicon carbide whiskers using the carbothermal nitridation process. A distinctive aspect of the present study lies in the use of the mechanical milling method to alter the regularity of the crystalline network of the silica sand. In order to optimise the processing parameters for the synthesis of silicon carbide, the concept of Taguchi's Design of Experiments was considered, the analysis being based on Taguchi's signal to noise ratio and variance techniques to obtain optimum combination of process parameters. Important factors influencing the formation of silicon carbide were the duration of the mechanical milling, followed by temperature, time and heating rate.
\end{abstract}

Keyword: B. Silicon carbide whiskers; Carbothermal nitridation; Taguchi's design of experiments method; Mechanical milling 